\title{
SYNCHRONIZATION OF OESTRUS AND SUBSEQUENT FERTILITY OF BEEF CATTLE FOLLOWING THE INTRAVAGINAL ADMINISTRATION OF GESTAGEN
}

\author{
HIROKAZU SHIMIZU, YUTAKA TOYODA, SABURO TAKEUGHI, \\ TOYOO KAWAI AND SADAHIKO ADACHI
}

Laboratory of Animal Reproduction, Faculty of Agriculture, Tohoku University, Sendai and Tottori National Stock Farm of Ministry of Agriculture and Forestry, Akasaki, Tottori Prefecture, Japan

(Received 13th Fuly 1966, revised 19th December 1966)

Among various ways of synchronizing oestrus with synthetic gestagen, the intravaginal route of administration as established for sheep by Robinson (1965) seemed to be interesting from the standpoint of both fundamental research work and practical application. No reports have appeared so far on the use of this technique in cattle and the authors, therefore, carried out an experiment using intravaginal gestagen-impregnated sponges. Although insufficient animals were used to draw a final conclusion, the results obtained seem to indicate some problems and these are described briefly.

Twelve Japanese Black cattle with good calving histories and regular oestrous cycles were used. They were still rearing their young, which had been born 3 to $6 \frac{1}{2}$ months earlier. The cows were divided into two groups according to the amount of steroid applied, i.e. Group 1, $100 \mathrm{mg}$; Group 2, $200 \mathrm{mg}$. Before treatment started at least two oestrous cycles of the normal range were recorded. Sponges were inserted at the 5th, 10th or 15th days after oestrus and allowed to remain for 18 days. The experiment commenced on 24th January 1966.

In a preliminary experiment, difficulty was experienced in retaining sponges but the problem was solved by the selection of a proper size and site of deposition. A cylindrical form $(10 \mathrm{~cm}$ in diameter) was made from a commercial polyurethane foam sheet $6.5 \mathrm{~cm}$ thick, specific gravity 0.02 (Takeda Chemical Industries, Ltd). The diameter selected had previously been shown to permit better retention than larger or smaller ones.

Before impregnating the sponges with steroid, $60 \mathrm{~cm}$ of suture thread was passed through the sponge as a marker to indicate retention in the cow. One hundred or $200 \mathrm{mg}$ of flurogestone acetate (SC-9880, 17 $\alpha$-acetoxy- $9 \alpha$ fluro-11 $\beta$-hydroxy-pregn-4-en-3,20-dione, Cronolone $\left.{ }^{\star}\right)$ was dissolved in $22 \mathrm{ml}$ of acetone to which had been added $3 \mathrm{ml}$ of 'Mastol U-Takeda' (an emulsion containing antibiotics and sulphonamides to prevent endometritis). The purpose of this was mainly to moisten the sponges in order to prevent loss of steroid during transportation of the sponges. Each sponge was then dipped 
into the resulting solution and dried in the air. After drying a $500 \mathrm{mg}$ Aureomycin Soluble Oblet (Lederle Japan, Ltd) was inserted into a hole, previously made in the centre of each sponge, as a bacteriostat. Finally each sponge was thinly coated with 'Mastol' ointment base (Takeda Chemical Industries Ltd) which had been softened by adding water to provide lubrication as an aid to insertion through a tube applicator.

A polyethylene tube $50 \mathrm{~cm}$ long and of $3.7 \mathrm{~cm}$ inner diameter, containing a sponge, was inserted into the vagina, the sponge being expelled with a wooden rod. The tube and rod were then withdrawn to leave the sponge in position and the protruding thread was cut at a point about $15 \mathrm{~cm}$ from the vulva. If the sponge was discharged a replacement was inserted as soon as possible.

Immediately before and after this procedure, rectal palpations of each cow were carried out to determine the ovarian conditions. Cows were inseminated artificially with semen of known quality once a day during the time oestrus was exhibited. Pregnancy diagnosis was made by rectal palpation more than 45 days after insemination. Twenty-nine cows at the 1st to 3rd months of lactation were used as untreated controls. The results are presented in Table 1.

The sponges failed to be retained by two of the twelve cows, one of which came into oestrus on the day the sponge was ejected. One cow exhibited oestrus, despite the retention of the sponge, on the 7 th day of insertion and at the anticipated time. The inhibition of oestrus was satisfactory except for the two cows mentioned above.

Oestrus occurred within 2 days after the withdrawal of sponges except for one cow in which it occurred on the 8th day. The duration of oestrus was either 1 or 2 days. On the day of oestrus typical oestrous patterns appeared, though the secretion of cervical mucus appeared to be less than was normally observed. Examination of the treated cows on the day of sponge withdrawal disclosed the presence of palpable follicles on the ovaries, congestion of the vaginal mucosa and dilation of the cervical orifice even in the absence of the oestrous patterns.

Comparing the results of Groups 1 and 2-though numbers were limitedno apparent differences were seen either in the recurrence of oestrus or in conception rate. One-half of the cows conceived to the first insemination and eleven out of twelve to the first and second insemination.

The conception rate of untreated controls was twenty out of twenty-nine to the first insemination and twenty-seven out of twenty-nine to the first and second insemination. The difference of the conception rate between treated and untreated group analysed by $\chi^{2}$-test was not significant both to the first and to the first plus second insemination.

In the group where treatment was started on the 15th day, changes were detected in the side (three out of four cows) and the position (one cow) of follicle development in the ovaries between the start and the cessation of treatment. However, small follicles found at the start of treatment in the ovaries of the group treated from the 10th day were all detected on the same side at the end of the treatment.

The conception rate to the first insemination was encouraging and, in fact, appeared to be normal. The appearance of oestrus in the present report was 


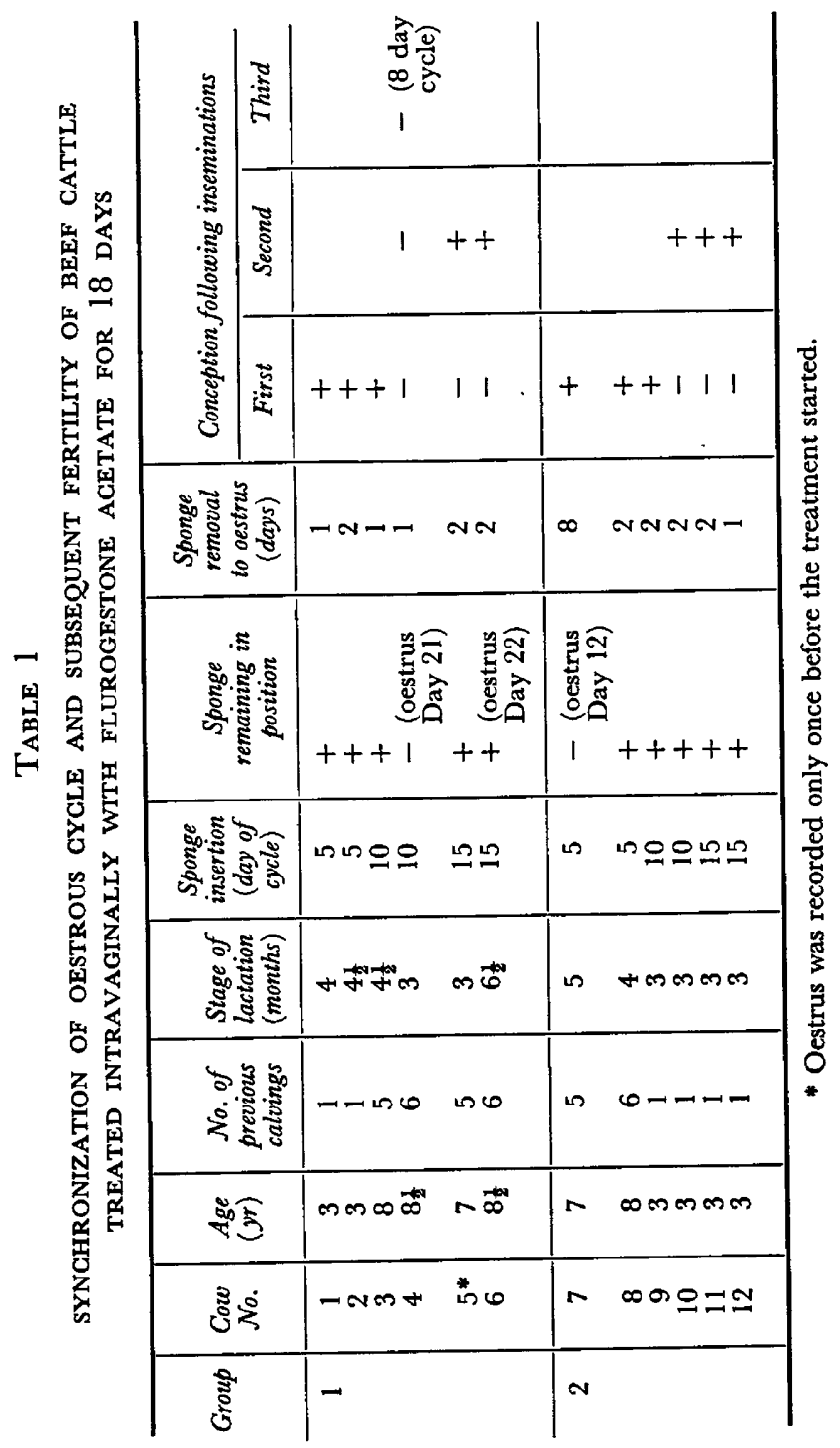


earlier than the results obtained by Robinson (1965) with flurogestone acetate on intravaginal sponges in sheep and that of oral treatment of beef cattle with chlormadinone (Takeuchi, Shimizu, Toyoda, Kawai \& Adachi, 1966, and others).

Inflammation or congestion of the vagina by contamination of bacteria or by the sponge itself did not cause problems in the present study, though infection with Pseudomonas aeruginosa was reported by Robinson (1965). Mild inflammation or congestion was, however, seen in a few cases during our preliminary trials.

\section{REFERENCES}

RoBrnson, T. J. (1965) Use of progestagen impregnated sponges inserted intravaginally or subcutaneously for the control of oestrus cycle in the sheep. Nature, Lond. 206, 39.

Takeuchi, S., Shimizu, H., Toyoda, Y., Kawai, T. \& Adachi, S. (1966) The synchronisation of oestrous cycle by oral gestagen and following fertility in the Japanese Native cattle. $\mathcal{F} a p . \mathcal{F}$. Anim. Reprod. 11, 115. 